\title{
ABORDAGENS SOBRE FOLGA ORGANIZACIONAL NAS PESQUISAS PUBLICADAS EM PERIÓDICOS INTERNACIONAIS: UM ENSAIO TEÓRICO
}

\author{
APPROACHES TO ORGANIZATIONAL SLACK IN RESEARCH \\ PUBLISHED IN INTERNATIONAL JOURNALS: \\ A THEORETICAL ESSAY
}

Recebido - 30.09.10

Aceito - 05.04.2011

Tiza Tamiozzo Quintas e Ilse Maria Beuren²

\section{Resumo}

O termo folga organizacional é reconhecido, algumas vezes, como o excesso de recursos empregados em uma organização. Como esse termo não tem uma definição propriamente dita, vem, ao longo dos anos, agregando conceitos de vários autores através de publicações científicas. Este estudo tem como objetivo analisar as abordagens sobre folga organizacional no contexto das pesquisas publicadas em periódicos científicos internacionais. Para tal, foi realizado um ensaio teórico considerando publicações em âmbito internacional, tendo como referência o termo folga organizacional. Os antecedentes de folga organizacional, num total de 43 artigos identificados, foram analisados segundo a classificação proposta por Sharfman et al. (1988), em três níveis de análise: indústria, organização e grupos de interesse. Os resultados do estudo mostram que as pesquisas sobre folga organizacional apresentam conceitos diversos e evolutivos e que as abordagens sobre inovação e estratégia são pontos-chave para as pesquisas relacionadas ao tema, pois foram as mais encontradas na literatura. Por outro lado, a mensuração desses tipos de folga de recursos ainda são pontos obscuros nas pesquisas desenvolvidas. Estudos como os de Cyert e March (1963), Bourgeois III (1981), Sharfman et al. (1988), Nohria e Gulati (1996) estão se ramificando para outros aspectos da organização. Assim conclui-se que pesquisas sobre definição de folga organizacional e de suas relações com aspectos do ambiente organizacional estão evoluindo e sinalizam discussões mais amplas em periódicos científicos internacionais.

Palavras-chave: Abordagens. Folga organizacional. Pesquisas. Periódicos internacionais. Ensaio teórico.

1 Mestre em Ciências Contábeis pela Universidade Regional de Blumenau (FURB). Brasil. E-mail: titinha.preta@gmail.com

2 Doutora em Controladoria e Contabilidade pela Faculdade de Economia, Administração e Contabilidade da Universidade de São Paulo (FEA-USP), professora do Programa de Pós-Graduação em Ciências Contábeis da Universidade Regional de Blumenau (FURB). Brasil. E-mail: ilse@furb.br 


\begin{abstract}
The term organizational slack is sometimes recognized as the excess resources in an organization. Since this term does not have a clear definition, it has accumulated over the years concepts of various authors through scientific publications. This study aims to examine the approaches to organizational slack in the context of research papers published in international scientific journals. To do so, a theoretical essay was performed based on international publications making reference to the term organizational slack. The antecedents of organizational slack, a total of 43 papers were analyzed according to the classification proposed by Sharfman et al. (1988), three levels of analysis: industry, organization and interest groups. The study results show that research on organizational slack have varied and evolving concepts and that the approaches to innovation and strategy are key points for research related to the topic, as they were the most found in the literature. However, the measurement of these types of resources slack is still an obscure point in the research developed. The studies of Cyert and March (1963), Bourgeois III (1981), Sharfman et al. (1988), Gulati and Nohria (1996) are branching out to other aspects of the organization. Though, it was concluded that research on definition of organizational slack and its relations with organizational environment aspects are evolving and signal further wider discussion in international scientific journals.
\end{abstract}

Keywords: Approaches. Organizational slack. Research. International journals. Theoretical essay.

\title{
1 INTRODUÇÃO
}

Folga organizacional é um tema inserido nas ciências sociais aplicadas e relaciona-se com a teoria comportamental da administração. Os primeiros estudos surgiram por volta da década de 1958. Tan e Peng (2003, p. 1250) comentam que, "embora Barnad (1938) tenha discutido o papel da folga precocemente em seu trabalho, o rótulo específico de Folga não tinha sido inventado até que March e Simon publicaram seu livro seminal em 1958". No entanto, os estudos sobre folga organizacional iniciaram com Cyert e March, em 1963, com a publicação do livro intitulado A Behavioral Theory of the Firm (A Teoria Comportamental da Firma), conhecido pelos pesquisadores do tema como um livro clássico (PRIETULA; WATSON, 2000).

A folga organizacional circunscreve-se ao ambiente interno da empresa. Sharfman et al (1988) descrevem três conjuntos de elementos que irão prever a quantidade e o tipo de folga realizada pela empresa: a) elementos do ambiente da empresa; b) características da própria organização; e c) valores e crenças dos acionistas. Neste sentido denota-se que a abordagem do tema requer um espectro ampliado de conhecimentos, muitos deles contemplados nas diversas disciplinas das ciências sociais aplicadas.

No entanto, na área contábil, poucos estudos foram identificados que explicitamente se referem a pesquisas sobre o tema folga organizacional. As pesquisas que relacionaram os controllers ao processo de tomada de decisão são um indício que a folga organizacional pode ser organizada e direcionada à contabilidade gerencial. Pesquisa publicada por Indjejikian e Matejka (2006) analisa as determinantes de folga organizacional para uma amostra de 104 controllers de unidades de negócios de grandes empresas descentralizadas e de forma específica investiga como os sistemas de gestão contábil afetam a folga organizacional.

$\mathrm{Na}$ área da administração, o tema tem sido explorado com maior ênfase, mas ainda requer maior atenção dada a sua importância em estudos organizacionais. Pesquisas sobre folga organizacional, embora com alguma longevidade em publicações internacionais, não se apresentam em volume considerável. No Brasil, poucas pesquisas que investigam o tema foram localizadas, destaca-se a dissertação de mestrado de Sender (2004), intitulada "O papel da folga organizacional nas empresas: um estudo em bancos brasileiros".

Rev. Adm. UFSM, Santa Maria, v. 4, n.1, p. 53-72, jan./abr. 2011 
Assim, com base no exposto, elaborou-se a seguinte pergunta de pesquisa: Quais as abordagens sobre folga organizacional são encontradas no contexto das pesquisas publicadas em periódicos científicos internacionais? Portanto, o estudo objetiva analisar as abordagens sobre folga organizacional no contexto das pesquisas publicadas em periódicos científicos internacionais. Neste sentido, foi realizado um ensaio teórico considerando publicações em âmbito internacional, tendo como referência o termo folga organizacional. Os antecedentes de folga organizacional foram analisados segundo a classificação proposta por Sharfman et al. (1988) em três níveis de análise: indústria, organização e grupos de interesse.

A pesquisa justifica-se pela relevância do tema em estudos organizacionais. A interdisciplinaridade da abordagem do tema, ao mesmo tempo em que o torna complexo, especialmente no que concerne à mensuração da folga entre os gestores das diversas divisões de uma organização, abre caminho para novas pesquisas e estudos sobre suas imbricações. A principal contribuição que se pretende neste estudo é apresentar as pesquisas que vêm sendo publicadas sobre folga organizacional e criar vínculos para futuras pesquisas na área.

Este estudo está estruturado em cinco seções, sendo que o primeira aborda a introdução. Em seguida é apresentada a conceituação de folga organizacional. Na terceira, a classificação dos antecedentes de folga da pesquisa e a classificação de cada pesquisa são analisadas conforme os antecedentes de folga organizacional identificados. Na sequência, discutem-se os resultados. Por fim, apresenta-se a conclusão do estudo realizado.

\section{CONCEITUAÇÃO DE FOLGA ORGANIZACIONAL}

As pesquisas desenvolvidas sobre folga organizacional apresentam, além da evolução nos procedimentos para investigar o tema em organizações e os resultados das pesquisas, acréscimos e/ou alterações as definições de folga organizacional. Essas definições, ao serem relacionadas entre si ao longo dos anos, foram se ampliando como se cada estudo, apesar de possuir objetivos, procedimentos, resultados e conclusões diferentes, acrescentasse algo à definição de folga organizacional.

Moses (1992, p. 42) destaca que "o conceito de folga é extensamente utilizado nas literaturas de teoria organizacional e estratégias empresariais, mas não há nenhuma única definição de consenso. Porém, a maioria das definições sugere a ideia de excesso de recursos que fornecem proteção e oportunidade".

Essa observação se deu a partir da pesquisa desenvolvida por Bourgeois III (1981), em que o autor apresentou um quadro com definições de folga organizacional, sendo que estas definições foram sintetizadas e apresentadas pelo autor como uma definição geral. No quadro 1, são descritas as definições de folga organizacional citadas por Bourgeois.

Verifica-se que Bourgeois III (1981) apresentou definições diversas sobre folga organizacional, em especial, de James March, que ao longo dos anos apresenta-se como um dos principais pesquisadores sobre o tema estudado. Em sequência, observa-se o surgimento de outras definições de folga organizacional, que se firmaram ao longo dos estudos como provenientes das pesquisas e definições de autores já apresentados por Bourgeois III (1981).

No quadro 2, apresentam-se definições de folga organizacional encontradas após a pesquisa realizada por Bourgeois III (1981), levantadas na revisão bibliográfica efetuada para este estudo. 


\begin{tabular}{|c|c|}
\hline Autores & Definição de Folga \\
\hline $\begin{array}{l}\text { Cyert e March } \\
\text { (1963) }\end{array}$ & $\begin{array}{l}\text { "A disparidade entre os recursos disponíveis da organização e os pagamentos exigidos para } \\
\text { manter a coligação" (p. 36). Cita como exemplos: o e xcesso de dividendos pagos aos } \\
\text { acionistas, preços mais baixos do que o necessário para manter os compradores, salários } \\
\text { maiores que o necessário para manter o empregado, gratificações para executivos, } \\
\text { crescimento de subunidades além das taxas relativas de contribuições. Além desta lista } \\
\text { menciona: "Fornecimento de recursos desviados" (p. 54). "Recursos funilados para a satisfação } \\
\text { dos objetivos do indivíduo e subgrupo (versus Organização)" (p. 98). }\end{array}$ \\
\hline Child (1972) & $\begin{array}{l}\text { "A margem ou excesso (desempenho que excede o nível de satisfação) que permite que a } \\
\text { coligação dominante de uma organização adote arranjos estruturais que outorgam com as } \\
\text { próprias preferências (versus. bons ajustes de ordens da teoria de contingência), mesmo com } \\
\text { alguns custos administrativos extras" (p. 11). }\end{array}$ \\
\hline $\begin{array}{l}\text { Cohen, March e } \\
\text { Olsen (1972) }\end{array}$ & $\begin{array}{l}\text { "A diferença entre os recursos da organização e da combinação de demandas feitas sobre ela" } \\
\text { (p. 12). }\end{array}$ \\
\hline $\begin{array}{l}\text { March e Olsen } \\
\text { (1976) }\end{array}$ & "A diferença entre os recursos existentes e as demandas ativadas" (p. 87). \\
\hline $\begin{array}{l}\text { Dimick e Murray } \\
\text { (1978) }\end{array}$ & $\begin{array}{l}\text { "Os recursos que uma organização tenha adquirido que não estão comprometidos com } \\
\text { despesas necessárias. Em essência, estes são recursos que podem ser utilizados de forma } \\
\text { discricionária" (p. 616). }\end{array}$ \\
\hline $\begin{array}{l}\text { Litschert e Bonham } \\
\text { (1978) }\end{array}$ & $\begin{array}{l}\text { Utilizando a definição de Cyert e March (1963), os autores ofereceram a seguinte sugestão de } \\
\text { operação: Folga = a variação da média entre as organizações comparáveis sobre: ROE, ROTA, } \\
\text { vendas líquidas, e lucro bruto com um por cento das vendas. }\end{array}$ \\
\hline March (1979) & $\begin{array}{l}\text { "Considerando que organizações não se aperfeiçoam sempre, elas acumulam recursos } \\
\text { disponíveis e oportunidades inexploradas que então se tornam um pára-choque contra tempos } \\
\text { ruins. Embora o pára-choque necessariamente não é pretendido, a folga produz desempenho } \\
\text { suave, reduzindo o desempenho durante bons tempos e melhorando -o durante períodos de } \\
\text { tempos ruins" (citado em Stanford GSB, p. 17). }\end{array}$ \\
\hline
\end{tabular}

Quadro 1 - Definições de folga organizacional

Fonte: Bourgeois III (1981, p. 30).

As definições encontradas sobre Folga Organizacional são vistas em perspectivas diferentes pelos autores, ou seja, cada pesquisador define com base no ambiente organizacional observado o tipo de folga organizacional. Com o pressuposto que cada organização é única e as tomadas de decisões são distintas das demais, a folga organizacional observada em cada pesquisa vai ser tratada de forma diferenciada pelos pesquisadores.

Cyert e March (apud BOURGEOIS III, 1981, p. 30) afirmam que folga organizacional pode ocorrer nas seguintes situações: "excesso de dividendos para acionistas; necessidade de baixa nos preços para manter os compradores; salários maiores que o necessário para manter os trabalhadores; gratificações para os executivos; crescimento das subunidades além da taxa relativa de contribuição". Essas situações podem ser encontradas em organizações, mas dependem da característica de cada uma. Bourgeois III (1981, p. 31) menciona que: 


\begin{tabular}{|l|l|}
\hline Autores & Definição de Folga \\
\hline Bourgeois III (1981) & $\begin{array}{l}\text { É a almofada de recursos reais ou potenciais que permite a uma organização se adaptar com } \\
\text { sucesso às pressões internas para ajuste ou às pressões externas para mudanças na política, } \\
\text { bem como dar início às mudanças nas estratégias em relação ao ambiente externo. }\end{array}$ \\
\hline $\begin{array}{l}\text { Antle e Eppen } \\
\text { (1985) }\end{array}$ & $\begin{array}{l}\text { É definido como o excesso de recursos alocados a lém do mínimo necessário para realizar as } \\
\text { tarefas atribuídas. }\end{array}$ \\
\hline Damanpour (1987) & $\begin{array}{l}\text { É a diferença entre os recursos que uma organização tem e o que ela minimamente exige para } \\
\text { manter suas operações. }\end{array}$ \\
\hline $\begin{array}{l}\text { Sharfman et al. } \\
\text { (1988) }\end{array}$ & $\begin{array}{l}\text { Adotam o conceito de Bourgeois (1981), mas duas diferenças importantes são abordadas. } \\
\text { Primeiro, na ordem de recursos a serem con siderados na folga, deve ficar visível para os } \\
\text { resultado de inventário mal feito às vezes pode ser efeito de folga, mas não representam folga } \\
\text { até seu propósito ter sido alterado. Segundo, os recursos variam na forma como podem ser } \\
\text { utilizados para proteger a empresa de elementos internos ou pressões externas. }\end{array}$ \\
\hline $\begin{array}{l}\text { Nohria e Gulati } \\
\text { (1996) }\end{array}$ & $\begin{array}{l}\text { Conjunto de recursos em uma organização que está além do mínimo necessário para produzir } \\
\text { um dado nível de saída na organização. }\end{array}$ \\
\hline George (2005) & $\begin{array}{l}\text { Folga são recursos potencialmente utilizáveis que podem ser desviados ou redistribuídos para a } \\
\text { realização de objetivos organizacionais. Esses recursos variam em tipo (por exemplo, capital } \\
\text { social ou financeiro) e forma (por exemplo, discricionário ou não discricionário). } \\
\text { atividades. }\end{array}$ \\
\hline
\end{tabular}

Quadro 2 - Definições de folga organizacional após a pesquisa de Bourgeois (1981) Fonte: elaboração própria.

Folga é tratada, às vezes, como algo que ambos seguem e promovem sucesso, e às vezes como um analógico para a ineficiência. Para evitar confusão, vale destacar que não se compara eficiência com sucesso. Uma organização pode ter sucesso (ou ser eficaz) e ineficiente ao mesmo tempo. Empresas com muita folga, por exemplo, serão menos eficientes por definição. Mas também poderão ser mais eficazes (e, possivelmente, mais rentáveis).

Uma das expressões mais utilizadas na literatura é o de relacionar folga aos recursos da empresa e assim chamá-la de folga de recursos. Essa folga de recursos representa, no ambiente organizacional, segundo Danneels (2008, p. 525), "uma reserva de recursos que está em excesso ao que é necessário para a continuação imediata das operações da empresa, e está, portanto, disponível para gastar na exploração das atividades".

No ambiente das empresas multinacionais e suas subsidiárias, Poynter e White (1985, p. 92) destacam que: 


\begin{abstract}
Folga organizacional é de fundamental importância. A quantidade de folga organizacional é relacionada com a capacidade da empresa para inovar e gerar novas estratégias. No entanto, se a folga não for cuidadosamente gerida, as estratégias resultantes das subsidiárias podem entrar em conflito com a matriz das multinacionais e com as estratégias sugeridas pelo ambiente competitivo.
\end{abstract}

Denota-se que os antecedentes de folga organizacional são formados com base em fatos ou ações que geraram folga dentro da organização. Conforme Sender (2004, p. 09), "o termo antecedentes refere-se aos fatores que, segundo a literatura examinada, podem influenciar a existência, a composição e o nível de folga organizacional".

\title{
3 ANTECEDENTES DE FOLGA ORGANIZACIONAL
}

Sender (2004) apresenta, em seu estudo, alguns autores que retratam em suas pesquisas os antecedentes de folga organizacional, entre eles: Marino e Lange (1983), Singh (1986), Sharfman et al. (1988) e Cheng e Kesner (1997). Os estudos sobre antecedentes de folga continuam sendo discutidos, pois cada pesquisador direciona os antecedentes aos tipos de folga organizacional identificados na organização foco do estudo.

Thompson (1967), assumindo que o uso primário de que folga é para proteger a empresa de seu ambiente, cita que Sharfman et al. (1988) apresentaram três fatores ambientais específicos que ajudam a moldar o nível de folga de uma empresa. Sharfman et al. (1988) publicaram pesquisa intitulada "Antecedentes de folga organizacional", propondo um modelo que descreve as condições em que os recursos de folga se desenvolvem.

Segundo Sharfman et al. (1988) e Sender (2004), os antecedentes de folga organizacional se dividem em três níveis de análise: indústria, organização e grupos de interesse. Sharfman et al. (1988) caracteriza-nos como segue:

a) Indústria - é representada pela sua estrutura, e possui dois elementos básicos, a natureza do ramo de produção e a fase do ciclo de vida da indústria. $\mathrm{Na}$ natureza do ramo de produção, são discutidas as escolhas básicas, isto é, se a empresa deve fornecer um produto ou um serviço ou os dois. Na fase do ciclo de vida da indústria, são percorridas as fases de vida da indústria e as suas necessidades de alterar as folgas de recursos;

b) Organização - representada pelas características da empresa (tamanho organizacional, desempenho, idade, tecnologia e estabilidade interna) que ajudam a explicar a variação nas quantidades e tipos de folga de recursos detidos;

c) Grupos de interesse - representado por valores e crenças da coalizão dominante, direcionado ao comportamento político, risco e tomada de decisão.

Os três níveis descritos são caracterizados como os antecedentes de folga organizacional. Conforme Sender (2004), cada nível descrito irá influenciar um determinado tipo de folga organizacional nas empresas. No quadro 3, são apresentados os antecedentes de folga organizacional considerados por Sender (2004), complementados com os identificados na revisão bibliográfica deste estudo. 


\begin{tabular}{|c|c|c|}
\hline Categoria & Descrição do Antecedente & Autor \\
\hline \multirow{7}{*}{ Indústria } & Velocidade e magnitude da mudança & $\begin{array}{l}\text { Sharfman et al. (1988) } \\
\text { Marino e Lange (1983) }\end{array}$ \\
\hline & Disponibilidade de recursos no mercado (generosidade) & Sharfman et al. (1988) \\
\hline & Natureza básica do output (produto ou serviço) & Sharfman et al. (1988) \\
\hline & Estágio da indústria no ciclo de vida & Sharfman et al. (1988) \\
\hline & $\begin{array}{l}\text { Organizações altamente afetadas pelo seu ambiente externo, mas } \\
\text { que têm pouco controle sobre ele }\end{array}$ & Cheng e Kesner (1997) \\
\hline & Pressões competitivas & $\begin{array}{l}\text { Singh (1986) } \\
\text { Marino e Lange (1983) }\end{array}$ \\
\hline & Mudanças na regulamentação & Marino e Lange (1983) \\
\hline \multirow{6}{*}{ Organização } & Tamanho & \multirow[t]{5}{*}{ Sharfman et al. (1988) } \\
\hline & Desempenho & \\
\hline & Idade & \\
\hline & Tecnologia & \\
\hline & Estabilidade interna & \\
\hline & Inovação* & $\begin{array}{l}\text { Damanpour (1991) } \\
\text { Nohria e Gulati (1996) }\end{array}$ \\
\hline \multirow{4}{*}{$\begin{array}{l}\text { Grupo de } \\
\text { Interesse }\end{array}$} & Comportamento político & \multirow[t]{2}{*}{ Sharfman et al. (1988) } \\
\hline & Ameaças e oportunidades percebidas & \\
\hline & Apoio à tomada de decisão* & Bateman e Zeithaml (1989) \\
\hline & $\begin{array}{l}\text { Conflitos de informações entre os proprietários e os gestores no que } \\
\text { diz respeito aos relatórios de evidenciação* }\end{array}$ & Antle e Fellingham (1990) \\
\hline
\end{tabular}

* Contribuições de outros autores identificados na revisão de literatura, que complementam os antecedentes de folga organizacional apresentados por Sender (2004, p. 11).

Quadro 3 - Antecedentes da folga organizacional

Fonte: Sender (2004, p. 11).

$\mathrm{Na}$ análise dos artigos pesquisados e selecionados referentes aos antecedentes de folga organizacional, para classificá-los, foram consideradas contribuições de outros autores como forma de tornar a classificação mais completa quanto aos antecedentes.

\subsection{Classificação quanto aos antecedentes de indústria}

Os artigos selecionados foram classificados segundo os antecedentes de folga organizacional apresentados no quadro 3 , sendo que, no quadro 4 , apresentam-se os relacionados aos antecedentes da indústria. 


\begin{tabular}{|c|c|}
\hline Autores & Objetivos da pesquisa \\
\hline $\begin{array}{l}\text { Marino e Lange } \\
\text { (1983) }\end{array}$ & $\begin{array}{l}\text { Verificar se as folgas têm aumentado ou diminuído nas organizações em comparação a um } \\
\text { estado anterior, sendo que as medidas absolutas destinam -se a identificar as empresas com mais } \\
\text { ou menos recursos de folga; e verificar qual das empresas em um determinado grupo possui os } \\
\text { maiores e mais baixos níveis de folga dos recursos. }\end{array}$ \\
\hline $\begin{array}{l}\text { Poynter e White } \\
\text { (1985) }\end{array}$ & $\begin{array}{l}\text { Explorar um dos fatores organizacionais que afetam as respostas das empresas subsidiárias } \\
\text { estrangeiras - a folga organizacional. Como exemplo dessa folga, tem -se as ne cessidades atuais } \\
\text { no excesso de recursos humanos. }\end{array}$ \\
\hline Singh (1986) & $\begin{array}{l}\text { Investigar a relação entre o desempenho organizacional e os riscos assumidos na tomada de } \\
\text { decisão organizacional. }\end{array}$ \\
\hline $\begin{array}{l}\text { Hambrick e } \\
\text { D'Aveni (1988) }\end{array}$ & $\begin{array}{l}\text { Explorar a falência de } 57 \text { grandes empresas e } 57 \text { sobreviventes utilizando a seleção de quatro } \\
\text { principais construtos estudados: iniciativa de domínio, capacidade de condução ambiental, } \\
\text { folga e desempenho. }\end{array}$ \\
\hline $\begin{array}{l}\text { Antle e } \\
\text { Fellingham } \\
\text { (1990) }\end{array}$ & $\begin{array}{l}\text { Explorar o poder de compromisso de reduzir ineficiências na alocação de recursos entre } \\
\text { empresas repetidas. }\end{array}$ \\
\hline $\begin{array}{l}\text { Duizendstraal e } \\
\text { Nentjes (1994) }\end{array}$ & $\begin{array}{l}\text { Analisar o impacto que os diferentes tipos de subsídios têm sobre a atribuição dos fatores de } \\
\text { produção entre as saídas formais e informais em uma organização sem fins lucrativos, que é um } \\
\text { monopólio vendedor de um produto não comercial. Folga organizacional, ou saída informal, } \\
\text { pode ser modelada como uma decisão variável em função da utilidade de uma organização sem } \\
\text { fins lucrativos, ao lado de uma meta formal de prestação de serviços. }\end{array}$ \\
\hline $\begin{array}{l}\text { Cheng e Kesner } \\
\text { (1997) }\end{array}$ & $\begin{array}{l}\text { Analisar se os recursos de folga têm efeitos diferenciais sobre a extensão de uma empresa em } \\
\text { resposta às mudanças ambientais. }\end{array}$ \\
\hline Young (1999) & $\begin{array}{l}\text { Testar uma estrutura de equação modelo para verificar o impacto dos mercados de capitais na } \\
\text { compensação de incentivos, folga organizacional e as inovações nas empresas listadas na NYSE e } \\
\text { NASDAQ. }\end{array}$ \\
\hline $\begin{array}{l}\text { Thomson e Millar } \\
\text { (2001) }\end{array}$ & $\begin{array}{l}\text { Analisar os argumentos contra e a favor à manutenção da folga durante a transformação de um } \\
\text { plano de compensação organizacional para empresas sem fins lucrativos. }\end{array}$ \\
\hline Bowen (2002) & $\begin{array}{l}\text { Apresentar uma perspectiva mais ampla de folga do que as vistas até o momento em estudos } \\
\text { sobre gestão ambiental, a fim de melhor compreender como diferentes tipos de folga pode m } \\
\text { facilitar e/ou dificultar a ecologização corporativa. }\end{array}$ \\
\hline $\begin{array}{l}\text { Richtnér e } \\
\text { Ahlström (2006) }\end{array}$ & $\begin{array}{l}\text { Identificar a folga organizacional e suas influências no desenvolvimento de novos projetos de } \\
\text { produtos. }\end{array}$ \\
\hline $\begin{array}{l}\text { Voss, } \\
\text { Sirdeshmukh e } \\
\text { Voss (2008) }\end{array}$ & $\begin{array}{l}\text { Examinar como recursos de folga interagem com a apreciação de ameaça ambiental no } \\
\text { processamento e exploração de produtos. }\end{array}$ \\
\hline $\begin{array}{l}\text { Latham e Braun } \\
\text { (2008) }\end{array}$ & $\begin{array}{l}\text { Investigar a interação entre folga e desempenho das empresas durante a recessão econômica, } \\
\text { respondendo à seguinte pergunta: Em que medida a folga organizacional no início de uma } \\
\text { recessão ajuda ou prejudica o desempenho posterior da empresa? }\end{array}$ \\
\hline
\end{tabular}

Quadro 4 - Classificação quanto aos antecedentes de indústria

Fonte: Dados da pesquisa. 
Os artigos analisados quanto aos antecedentes de indústria de folga organizacional apresentaram, como objetivos, aspectos que condizem com os apresentados no quadro 3, que são: pressões competitivas; mudanças na regulamentação; disponibilidades de recursos no mercado; velocidade e magnitude da mudança; estágio da indústria no ciclo de vida, organizações altamente afetadas pelo seu ambiente externo, mas que têm pouco controle sobre ele; e natureza básica do output (produtos e serviços). Cada artigo classificado corresponde, sob o ponto de vista qualitativo, a um dos aspectos anteriormente descritos.

\section{a) Pressões competitivas}

A pesquisa de Singh (1986) está direcionada a identificar a relação entre o desempenho organizacional e os riscos assumidos na tomada de decisão organizacional. Sua classificação como pressões competitivas deve-se ao fato de a folga de recursos gerar pressões competitivas no mercado. Apesar de o estudo poder ser classificado quanto aos grupos de interesse e organização, a busca pela relação entre desempenho e tomada de risco nas pesquisas de folga organizacional, dirige-a para a situação e indagação de que pretende entender até que ponto a folga de recursos influencia.

Young (1999) apresenta uma pesquisa com o objetivo de testar uma estrutura de equação modelo para verificar o impacto dos mercados de capitais na compensação de incentivos, folga organizacional e as inovações nas empresas listadas na NYSE e NASDAQ. Apresenta que a relação entre compensação de incentivos, folga organizacional e as inovações podem ter relações com as pressões competitivas de mercado ao testar o modelo. Observa-se que esse tipo de pressão competitiva está atrelado ao processo de tomada de decisão, em que se decide a forma de conduzir a organização diante das mudanças de ambiente.

\section{b) Mudanças na regulamentação}

A pesquisa de Thomson e Millar (2001), ao analisar os argumentos contra e a favor da manutenção da folga durante a transformação de um plano de compensação organizacional para empresas sem fins lucrativos, evidencia que há relação com folga organizacional no sentido das folgas de recursos influenciarem os investimentos e estratégias nas organizações.

A pesquisa de Latham e Braun (2008) investiga a interação entre folga e desempenho das empresas durante a recessão econômica. As mudanças de regulamentação ocorridas dentro da empresa durante o processo de recessão econômica fazem com que gestores utilizem os recursos de folga como forma de ajustar a empresa a um modelo que melhor se ajuste ao mercado.

\section{c) Disponibilidade de recursos}

A pesquisa de Marino e Lange (1983), quanto a verificar se as folgas têm aumentado ou diminuído nas organizações em comparação a um estado anterior, demonstra a preocupação dos pesquisadores em identificar as disponibilidades de recursos nas empresas e se as mesmas têm mais ou menos recursos de folga. Isso do ponto de vista da contabilidade é uma das atribuições dos controllers das empresas. Analisar essa variável diante das folgas de recursos mostra a preocupação das empresas quanto aos investimentos futuros, que está interligada aos demais antecedentes, como o de grupos de interesse na relação de tomada de decisão e gestão contábil, e aos antecedentes da organização quanto às avaliações de desempenho da empresa.

As pesquisas de Hambrick e D'Aveni (1988) e Bowen (2002) apresentam relações fortes entre as disponibilidades de recursos de folga organizacional e as formas de desempenho e gestão ambiental da empresa.

\section{d) Velocidade e magnitude da mudança}

Antle e Fellingham (1990), em suas pesquisas sobre o compromisso de reduzir ineficiências na alocação de recursos entre empresas, e de Cheng e Kesner (1997), ao analisar se os 
recursos de folga têm efeitos diferenciais sobre a extensão de uma empresa em resposta às mudanças ambientais, mostram que a gestão dos recursos de folga organizacional estão atrelados, de certa forma, à velocidade e magnitude das mudanças nas empresas. Este aspecto está também direcionado aos grupos de interesse da organização.

e) Estágio da indústria no ciclo de vida, organizações altamente afetadas pelo seu ambiente externo, mas que têm pouco controle sobre ele

A pesquisa de Poynter e White (1985), ao explorar um dos fatores organizacionais que afetam as respostas das empresas subsidiárias estrangeiras (a folga), aponta as necessidades atuais no excesso de recursos humanos. Verifica-se que sua classificação quanto aos estágios da indústria no ciclo de vida está relacionada à forma como as subsidiárias estrangeiras tem seu processo industrial afetado pelo ambiente externo a que está sujeita. A cultura e os costumes da organização em determinado país são afetados, assim como as condições de trabalho e salários, isto é, os recursos humanos também são afetados.

A pesquisa em questão está relacionada também aos grupos de interesse e organização. Quanto aos grupos de interesse, a função dos controllers é verificar se o excedente de recursos humanos nas demais unidades de negócios da empresa são pontos-chave para um controle efetivo. No que concerne às organizações, esta pesquisa poderia se relacionar ao tamanho e desempenho da organização, o que necessita de uma reorganização dos recursos humanos quanto ao controle dos cargos, horários e salários dos funcionários. Um ponto ainda obscuro nas pesquisas de folga organizacional é até que ponto a folga de recursos humanos prejudica uma empresa.

Voss, Sirdeshmukh e Voss (2008) examinaram como os recursos de folga interagem com apreciação de ameaça ambiental para influenciar o processamento e a exploração de produtos. A folga organizacional relaciona-se aos ciclos de vida em que as empresas estão inseridas e seu processo no ambiente de mercado.

\section{f) Natureza básica do output (produtos e serviços)}

Duizendstraal e Nentjes (1994) analisaram o impacto que os diferentes tipos de subsídios têm sobre a atribuição dos fatores de produção entre as saídas formais e informais em uma organização sem fins lucrativos, que é um monopólio vendedor de um produto não comercial. A folga organizacional, ou saída informal, pode ser modelada como uma decisão variável em função da utilidade de uma organização sem fins lucrativos, ao lado de meta formal de prestação de serviços.

Richtnér e Ahlström (2006) identificaram a folga organizacional e suas influências no desenvolvimento de novos projetos de produtos. A percepção de folga organizacional nesse estágio de desenvolvimento de novos projetos de produtos em uma empresa é de significativa importância para gerenciar os tipos de folga que podem se manifestar no processo, além de conseguir manter controle em determinados aspectos em que a folga possa ser absorvida em maior escala, como, por exemplo, no excesso de custos e gastos gerais despendidos em sua execução.

\subsection{Classificação quanto aos antecedentes de organização}

Os artigos selecionados foram classificados segundo os antecedentes de folga organizacional apresentados no quadro 3, sendo que, no quadro 5, são apresentados os artigos relacionados aos antecedentes de organização. 


\begin{tabular}{|c|c|}
\hline Autores & Objetivos da pesquisa \\
\hline Damanpour (1991) & $\begin{array}{l}\text { A pesquisa apresentou três propostas: a) Testar a hipótese da relação entre os fatores organizacionais e } \\
\text { inovação e avaliar a validade da hipótese da instabilidade no resultado das pesquisas à inovação; b) Explorar } \\
\text { quais dimensões de inovação moderam eficazmente o relacionamento entre inovação e as suas correlações } \\
\text { ou causas determinantes ; e c) Testar algumas das teorias existen tes da inovação utilizando os dados } \\
\text { agregados, com um objetivo mais amplo, o de identificar direções para futuras pesquisas empíricas } \\
\text { orientadas para o desenvolvimento de uma contingência da teoria organizacional da inovação. }\end{array}$ \\
\hline $\begin{array}{l}\text { Zajac, Golden e } \\
\text { Shortell (1991) }\end{array}$ & $\begin{array}{l}\text { Examinar a utilização de uma recém-desenvolvida forma organizacional para fins de inovação, ou seja, uma } \\
\text { associação de empreendimentos conjuntos (joint ventures), que possui características de ambas, as } \\
\text { tradicionais joint ventures, e de risco corporativo. }\end{array}$ \\
\hline $\begin{array}{l}\text { Nohria e Gulati } \\
\text { (1996) }\end{array}$ & $\begin{array}{l}\text { Discutir uma forma de reconciliar o debate teórico, reconhecendo que o relacionamento entre folga e } \\
\text { inovação é curvilíneo. Pouca folga para a inovação é tão ruim como muita folga. }\end{array}$ \\
\hline $\begin{array}{l}\text { Wally e Fong } \\
(2000)\end{array}$ & $\begin{array}{l}\text { Analisar as hipóteses de que três fatores organizacionais (desempenho, folga organizacional e débito) afetam } \\
\text { uma decisão estratégica da empresa em relação ao calendário de entrada de um novo produto no mercado }\end{array}$ \\
\hline $\begin{array}{l}\text { Geiger e Cashen } \\
\text { (2002) }\end{array}$ & $\begin{array}{l}\text { Estender os estudos realizados por Nohria e Gulati (1996) examinando o impacto da folga organizacional na } \\
\text { inovação por uma perspectiva multidimensional. Assim este estudo examina folga em três dimensões que } \\
\text { são comuns em pesquisas de gestão: folga disponível, folga recuperável e potencial de folga. }\end{array}$ \\
\hline $\begin{array}{l}\text { Pinsonneault e } \\
\text { Kraemer (2002) }\end{array}$ & $\begin{array}{l}\text { Explorar o papel que a tecnologia da informação (TI) desempenha na redução do tamanho organizacional } \\
\text { por meio do estudo de duas empresas médias das cidades americanas, ao longo de um período de } 10 \text { anos } \\
(1985-1995) \text {. }\end{array}$ \\
\hline Tan e Peng (2003) & $\begin{array}{l}\text { Debater a condução de dois estudos sobre hipóteses competitivas das teorias da organização e agência } \\
\text { atreladas ao contexto de transições econômicas. Especificamente, focados em empreendimentos nacionais } \\
\text { da China, com base em pesquisas e dados de arq uivos, investigaram se a folga organizacional contribui ou } \\
\text { inibe o desempenho das empresas. }\end{array}$ \\
\hline Greve (2003) & $\begin{array}{l}\text { A partir de um modelo integrado de desenvolvimento de inovação lançado na teoria comportamental das } \\
\text { empresas, a pesquisa busc ou analisar os problema s de desenvolvimento e adequação dos processos de } \\
\text { decisão e gerar hipóteses sobre como o desempenho e a folga afetam o P\&D e sobre como afetam o } \\
\text { desempenho de taxas de inovação. }\end{array}$ \\
\hline George (2005) & $\begin{array}{l}\text { Articular as relações entre as diferentes formas de folga financeira e do desempenho das empresas } \\
\text { privativamente seguradas. }\end{array}$ \\
\hline $\begin{array}{l}\text { Love e Nohria } \\
\text { (2005) }\end{array}$ & $\begin{array}{l}\text { Enfatizar o nível de folga organizacional como uma contingência importante e examinar outras duas } \\
\text { contingências: a) Se o espaço de redução de tamanho é estreito (restrito a reduçôes de pessoas) ou amplo } \\
\text { (envolvendo reajustamento da organização); e b) Se a redução d o tamanho está conduzindo à dinâ mica } \\
\text { (quando o desempenho for estável ou melhorado) ou reativa (quando o desempenho declinar). }\end{array}$ \\
\hline $\begin{array}{l}\text { Herold, Jayaraman } \\
\text { e Narayanaswamy } \\
\text { (2006) }\end{array}$ & 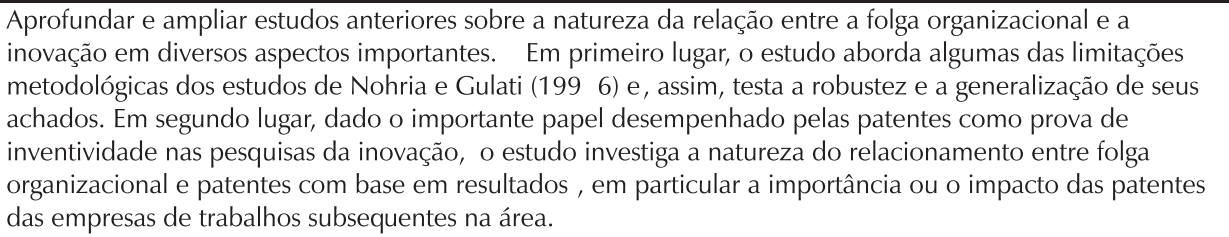 \\
\hline $\begin{array}{l}\text { Chen e Miller } \\
\text { (2007) }\end{array}$ & $\begin{array}{l}\text { Analisar as considerações que molda } m \text { e constrange } \mathrm{m} \text { a alocação de recursos às atividades em P\&D. Os } \\
\text { argumentos teóricos e testes empíricos endereçam para duas amplas categorias de causas determinantes e } \\
\text { comportamentais da busca intensiva de P\&D: situações e institucionais. }\end{array}$ \\
\hline $\begin{array}{l}\text { Dembla, Palvia e } \\
\text { Brooks (2007) }\end{array}$ & $\begin{array}{l}\text { Determinar o efeito que fatores contextuais, como maturidade de sistemas de informação, atributos } \\
\text { organizacionais e características ambientais, têm na utilização percebida e a adoção de serviços web- } \\
\text { habilitados para disseminação de informação nas organizações. }\end{array}$ \\
\hline
\end{tabular}

\section{Quadro 5 - Classificação quanto aos antecedentes de organização}

Fonte: Dados da pesquisa. 
Os artigos analisados quanto aos antecedentes de organização de folga organizacional apresentaram como objetivos aspectos que correspondem aos apresentados no quadro 3: tamanho, desempenho, idade, tecnologia, estabilidade interna e inovação. Cada artigo classificado relaciona-se com um dos aspectos acima descritos.

\section{a) Tamanho}

Love e Nohria (2005) objetivaram enfatizar o nível de folga organizacional como uma contingência importante e examinar outras duas contingências: a) Se o espaço de redução de tamanho é estreito (restrito a redução de pessoa) ou amplo (envolvendo reajustamento da organização); e b) Se a redução do tamanho está conduzindo à dinâmica (quando o desempenho for estável ou melhorado) ou reativa (quando o desempenho declinar).

\section{b) Desempenho}

Wally e Fong (2000) analisaram as hipóteses de que três fatores organizacionais (desempenho, folga organizacional e débito) afetam uma decisão estratégica da empresa em relação ao calendário de entrada de um novo produto no mercado.

Tan e Peng (2003) debateram dois estudos sobre hipóteses competitivas das teorias da organização e agência, atreladas ao contexto de transições econômicas. Especificamente, focados em empreendimentos nacionais da China, com base em pesquisas e dados de arquivos, investigaram se a folga organizacional contribui ou inibe o desempenho das empresas.

Greve (2003), com base em um modelo integrado de desenvolvimento de inovação, lançado na teoria comportamental das empresas, buscou analisar os problemas de desenvolvimento e adequação dos processos de decisão e gerar hipóteses sobre como o desempenho e a folga afetam o P\&D e sobre como afetam o desempenho de taxas de inovação.

\section{c) Idade}

Não se identificaram estudos que reportam o elemento idade da organização.

\section{d) Tecnologia}

Pinsonneault e Kraemer (2002) exploraram o papel que a tecnologia da informação (TI) desempenha na redução do tamanho organizacional por meio de um estudo em duas empresas médias das cidades americanas, ao longo de um período de 10 anos (1985-1995).

Chen e Miller (2007) analisaram as considerações que moldam e constrangem a alocação de recursos para as atividades em P\&D. Os argumentos teóricos e testes empíricos endereçam para duas amplas categorias de causas determinantes e comportamentais da busca intensiva de P\&D: situações e institucionais.

Dembla, Palvia e Brooks (2007) objetivaram determinar o efeito que fatores contextuais como maturidade de sistemas de informação, atributos organizacionais e características ambientais, têm na utilização percebida e a adoção de serviços web-habilitados para disseminação de informação nas organizações.

\section{e) Estabilidade interna}

George (2005) buscou articular as relações entre as diferentes formas de folga financeira e o desempenho das empresas privativamente seguradas. Essa relação sugere que as empresas estão utilizando a folga como forma de estabilidade interna entre os processos e ciclos financeiros na empresa. 


\section{f) Inovação}

A pesquisa de Damanpour (1991) apresentou três propostas: a) testar a hipótese da relação entre os fatores organizacionais e inovação e avaliar a validade da hipótese da instabilidade no resultado das pesquisas à inovação; b) explorar quais dimensões de inovação moderam eficazmente o relacionamento entre inovação e as suas correlações ou causas determinantes; e c) testar algumas das teorias existentes da inovação utilizando os dados agregados, com um objetivo mais amplo, o de identificar direções para futuras pesquisas empíricas orientadas para o desenvolvimento de uma contingência da teoria organizacional da inovação.

Zajac, Golden e Shortell (1991) examinaram a utilização de uma recém-desenvolvida forma organizacional para fins de inovação, ou seja, uma associação de empreendimentos conjuntos (joint ventures), que possuem características de ambas, as tradicionais joint ventures, e de risco corporativo interno.

Nohria e Gulati (1996) discutiram uma forma de reconciliar o debate teórico, reconhecendo que o relacionamento entre folga e inovação é curvilíneo. Pouca folga para a inovação é tão ruim como muita folga.

Geiger e Cashen (2002) estenderam os estudos realizados por Nohria e Gulati (1996) examinando o impacto da folga organizacional na inovação em uma perspectiva multidimensional. Assim o estudo examinou folga em três dimensões que são comuns em pesquisas de gestão: folga disponível, folga recuperável e potencial de folga.

Herold, Jayaraman e Narayanaswamy (2006) aprofundaram e ampliaram estudos anteriores sobre a natureza da relação entre a folga organizacional e inovação em diversos aspectos importantes. Em primeiro lugar, o estudo buscou abordar algumas das limitações metodológicas dos estudos de Nohria e Gulati (1996) e, assim, testar a robustez e a generalização de seus achados. Em segundo lugar, dado o importante papel desempenhado pelas patentes como prova de inventividade nas pesquisas da inovação, o estudo investigou a natureza do relacionamento entre folga organizacional e patentes com base em resultados, em particular a importância ou o impacto das patentes das empresas em trabalhos subsequentes.

Esses estudos mostram que as pesquisas em si estão interligadas no que concerne ao processo de inovação e que cada pesquisa, de certa forma, traduz-se como uma continuação do que já foi pesquisado sobre inovação e folga organizacional.

\subsection{Classificação quanto aos antecedentes de grupo de interesse}

Os artigos selecionados foram classificados segundo os antecedentes de folga organizacional apresentados no quadro 3, sendo que, no quadro 6, são apresentados os artigos classificados quanto aos antecedentes de grupo de interesse.

Os artigos analisados quanto aos antecedentes de grupo de interesse de folga organizacional apresentaram como objetivos aspectos apresentados no quadro 3: comportamento político, ameaças e oportunidades percebidas, apoio à tomada de decisão e conflitos de informações entre os proprietários e os gestores no que diz respeito aos relatórios de evidenciação. Cada artigo, abaixo classificado, relaciona-se com um dos aspectos anteriormente descritos.

\section{a) Comportamento político}

Antle e Eppen (1985) buscaram conciliar três fatos estilizados sobre a distribuição de recursos nas empresas (por exemplo, orçamento de capital) e mostrar que eles estão relacionados à presença de assimetria da informação entre os sócios da empresa. Os fatos são: a) a 


\begin{tabular}{|c|c|}
\hline Autores & Objetivos da pesquisa \\
\hline $\begin{array}{l}\text { Antle e Eppen } \\
\text { (1985) }\end{array}$ & $\begin{array}{l}\text { Conciliar três fatos estilizados sobre a distribuição de recursos nas empresas (por exemplo, orçamento } \\
\text { de capital) e mos trar que eles estão relacionados à presença de assimetria da informaçãa entre os } \\
\text { sócios da empresa. Os fatos são: a) a existência de folga organizacional; b) o racionamento de } \\
\text { recursos dentro das organizações; c) o corte de taxa declarado para aceitar projetos em empresas de } \\
\text { capital é muitas vezes maior do que a taxa de juros do mercado. }\end{array}$ \\
\hline Bromiley (1991) & $\begin{array}{l}\text { Determinar a quantidade de riscos a que uma empresa se compromete e verificar quais são os efeitos } \\
\text { que a tomada de risco tem sobre o desempenho econômico futuro. }\end{array}$ \\
\hline $\begin{array}{l}\text { Davis e Stout } \\
\text { (1992) }\end{array}$ & $\begin{array}{l}\text { Fornecer evidências para as causas das grandes aquisições majoritárias nos Estados Unidos e por que } \\
\text { estas não são facilmente acomodadas pelas atuais teorias organizacionais. }\end{array}$ \\
\hline Haveman (1993) & $\begin{array}{l}\text { Examinar a relação entre mudança e ta manho organizacional. Partindo da hipótese de que se } \\
\text { tamanho organizacional indica isolamento político e grau de burocratização, então as grandes } \\
\text { organizações mudarão menos que as pequenas organizações. E se o tamanho organizacional é } \\
\text { relacionado à posse d e folga de recursos, estruturas diferenciadas e de scentralizadas, e de poder de } \\
\text { mercado, então grandes organizações serão mais líquidas que as pequenas organizações. }\end{array}$ \\
\hline Geppert (1996) & Examinar empiricamente como a aprendizagem gerencial cria ou reduz folga organizacional. \\
\hline $\begin{array}{l}\text { Miller e Leiblein } \\
\text { (1996) }\end{array}$ & $\begin{array}{l}\text { Testar um modelo comportamental em relação ao risco-retorno da empresa na qual as relações de } \\
\text { risco são conceituadas em termos de resultados negativos como resultados discrepantes. Com base na } \\
\text { teoria comportamental das empresas (Cyert e March, 1963) desenvolver hipóteses para serem } \\
\text { testadas em pesquisas relativas às relações entre risco negativo e retornos que permitem efeitos } \\
\text { moderados associados à folga organizacional. }\end{array}$ \\
\hline $\begin{array}{l}\text { Chattopadhyay, } \\
\text { Glick e Huber } \\
\text { (2001) }\end{array}$ & $\begin{array}{l}\text { Testar um modelo no qual ameaças e oportunidades conduzem diretamente a diferentes ações } \\
\text { organizacionais e comparar isto a um modelo no qual características organizacionais moderam ações } \\
\text { organizacionais em resposta à ameaças e oportunidades. }\end{array}$ \\
\hline $\begin{array}{l}\text { Lee e Grewal } \\
(2004)\end{array}$ & $\begin{array}{l}\text { Criar um modelo de framework que compreenda o impacto das respostas estratégicas sobre o } \\
\text { desempenho e a empresa; o papel dos recursos organizacionais na relação entre as respostas } \\
\text { estratégicas e o desempenho das empresas. Admitindo que uma resposta estratégica possa ser } \\
\text { classificada de acordo com as dimensões de grandeza, domínio e velocidade, além de classificar em } \\
\text { recursos organizacionais como tangíveis e intangíveis. }\end{array}$ \\
\hline $\begin{array}{l}\text { Mishina, Pollock e } \\
\text { Porac (2004) }\end{array}$ & $\begin{array}{l}\text { Examinar como lógicas de crescimento da gestão a combinação de recursos financeiros e recursos } \\
\text { humanos de folga para influenciar o crescimento da receita em curto prazo de uma amostra de } 112 \\
\text { empresas industriais. }\end{array}$ \\
\hline Gary (2005) & $\begin{array}{l}\text { Em teoria, a partilha dos recursos deve produzir benefícios econômicos relacionados às } \\
\text { multiempresas, mas a extensa investigação empírica permanece equívoca. Assim, esta pesquisa } \\
\text { examina o processo de implementação de uma estratégia de diversificação relacionada. }\end{array}$ \\
\hline $\begin{array}{l}\text { Indjejikian e } \\
\text { Matejka (2006) }\end{array}$ & $\begin{array}{l}\text { Analisar as determinantes de folga organizacional para uma amostra de } 104 \text { controllers de unidades } \\
\text { de negócios de grandes empresas descentralizadas e focar em particular em como sistemas de gestão } \\
\text { contábil afetam a folga organizacional. }\end{array}$ \\
\hline lyer e Miller (2008) & plicação comportamental para o momento de decisão de aquisição. \\
\hline
\end{tabular}

Quadro 6 - Classificação quanto aos antecedentes de grupo de interesse

Fonte: Dados da pesquisa. 
existência de folga organizacional; b) o racionamento de recursos dentro das organizações; b) o corte de taxa declarado para aceitar projetos em empresas de capital é muitas vezes maior do que a taxa de juros do mercado.

Davis e Stout (1992) objetivaram fornecer evidências para as causas das grandes aquisições majoritárias nos Estados Unidos e porque estas não são facilmente acomodadas pelas atuais teorias organizacionais.

Haveman (1993) examinou a relação entre mudança e tamanho organizacional. Partindo da hipótese de que, se tamanho organizacional indica isolamento político e grau de burocratização, então as grandes organizações mudarão menos que as pequenas organizações. E se o tamanho organizacional está relacionado à posse de folga de recursos, estruturas diferenciadas e descentralizadas, e de poder de mercado, então grandes organizações serão mais líquidas que as pequenas organizações.

\section{b) Ameaças e oportunidades percebidas}

Bromiley (1991) buscou determinar a quantidade de riscos a que uma empresa se compromete; e verificar quais são os efeitos que a tomada de risco tem sobre o desempenho econômico futuro.

Miller e Leiblein (1996) testaram um modelo comportamental em relação ao risco-retorno da empresa, no qual as relações de risco são conceituadas em termos de resultados negativos como resultados discrepantes. Com base na teoria comportamental das empresas, Cyert e March (1963) objetivaram desenvolver hipóteses para serem testadas em pesquisas relativas às relações entre risco negativo e retorno que permitem efeitos moderados associados à folga organizacional.

Chattopadhyay, Glick e Huber (2001) objetivaram testar um modelo no qual ameaças e oportunidades conduzem diretamente a diferentes ações organizacionais e comparar isto a um modelo no qual características organizacionais moderam ações organizacionais em resposta às ameaças e oportunidades.

\section{c) Apoio à tomada de decisão}

Lee e Grewal (2004) criaram um modelo de framework que compreenda o impacto das respostas estratégicas sobre o desempenho e a empresa; o papel dos recursos organizacionais na relação entre as respostas estratégicas e o desempenho das empresas. Admitindo que uma resposta estratégica possa ser classificada de acordo com as dimensões de grandeza, domínio e velocidade, além de classificarem recursos organizacionais como tangíveis e intangíveis.

Mishina, Pollock e Porac (2004) buscaram examinar como lógicas de crescimento da gestão combinam com os recursos financeiros e recursos humanos de folga para influenciar o crescimento da receita em curto prazo de uma amostra de 112 empresas industriais.

Gary (2005) considerou que, em teoria, a partilha dos recursos deve produzir benefícios econômicos relacionados às multiempresas, mas a extensa investigação empírica permanece equívoca. Assim, sua pesquisa examinou o processo de implementação de uma estratégia de diversificação relacionada. Iyer e Miller (2008) propuseram uma explicação comportamental para o momento de decisão de aquisição.

\section{d) Conflitos de informações entre os proprietários e os gestores no que diz res- peito aos relatórios de evidenciação}

Geppert (1996) examinou empiricamente como a aprendizagem gerencial cria ou reduz folga organizacional. Indjejikian e Matejka (2006) analisaram as determinantes de folga organizacional para uma amostra de 104 controllers de unidades de negócios de grandes empresas descentralizadas e focaram em particular como sistemas de gestão contábil afetam a folga organizacional. 
Neste quesito, percebe-se que as funções do controller têm relação direta com as pesquisas de folga de recursos que se preocupam com a assimetria de informação ligada à teoria de agência.

\subsection{Artigos sem classificação quanto aos antecedentes}

Entre os artigos selecionados, alguns não permitiram seu enquadramento nas categorias de antecedentes de folga organizacional apresentados no quadro 3. Assim, no quadro 7, são apresentados os artigos sem classificação quanto aos antecedentes.

\begin{tabular}{|l|l|}
\hline Autores & Objetivos da pesquisa \\
\hline $\begin{array}{l}\text { Litschert e } \\
\text { Bonham (1978) }\end{array}$ & $\begin{array}{l}\text { Apresentar um modelo teórico que identifica de forma precisa as relações entre estratégia e } \\
\text { estrutura organizacional e, ainda, integrar aspectos da teoria da contingência. }\end{array}$ \\
\hline $\begin{array}{l}\text { Bourgeois III } \\
\text { (1981) }\end{array}$ & $\begin{array}{l}\text { Sugerir uma definição utilizável sobre folga organizacional que seja consistente com a literatura; } \\
\text { Analisar as diversas funções de folga sugeridas por diversos autores; A partir das funções, } \\
\text { apresentar alguns métodos de operacionalização dos conceitos de folga que facilite futuras } \\
\text { pesquisas empíricas. }\end{array}$ \\
\hline $\begin{array}{l}\text { Sharfman et al. } \\
\text { (1988) }\end{array}$ & $\begin{array}{l}\text { Apresentar um modelo de conjunto de elementos que prevê a quantidade e tipos de folga } \\
\text { realizadas pela empresa. }\end{array}$ \\
\hline $\begin{array}{l}\text { Prietula e Watson } \\
\text { (2000) }\end{array}$ & $\begin{array}{l}\text { O que intriga pesquisadores das ciências organizacionais, em parte, é como ligar o que eles } \\
\text { descobrem sobre comportamento organizacional ao que eles observam sobre desempenho } \\
\text { econômico. O propósito desse artigo foi explorar essa ligação revisando uma teoria e um } \\
\text { modelo computacional articulado há mais de 30 anos - uma teoria comportamental das } \\
\text { organizações (CYERT; MARCH, 1963). }\end{array}$ \\
\hline Bansal (2003) & $\begin{array}{l}\text { O propósito desse estudo foi explicar as respostas organizacionais pela análise do fluxo de } \\
\text { questões. }\end{array}$ \\
\hline
\end{tabular}

\section{Quadro 7 - Sem classificação quanto aos antecedentes}

Fonte: Dados da pesquisa.

As pesquisas apresentadas no quadro 7 foram descritas como sem classificação quanto aos antecedentes de folga organizacional, pois não se enquadravam em nenhuma das características descritas no quadro de antecedentes da indústria, organização e grupos de interesse.

Observa-se que os autores Bourgeois III e Sharfman et al. $(1981$; 1988) apresentaram pesquisas com objetivos diferentes, mas que se complementam diante das características da folga: definições e tipos. Suas pesquisas serviram como fonte para outros estudos e como antecedentes para as demais pesquisas que aqui foram classificadas em três categorias. 


\section{CONSIDERAÇÕES FINAIS}

Este estudo objetivou analisar as abordagens sobre folga organizacional no contexto das pesquisas publicadas em periódicos científicos internacionais. Para tal, foi realizado um ensaio teórico considerando publicações em âmbito internacional, tendo como referência o termo folga organizacional.

Os achados da pesquisa mostram que os estudos sobre folga organizacional são amplos e complexos. A descrição dos antecedentes de folga organizacional, expostos por Sender (2004) e tomados como referência nesta pesquisa, mostram que a folga organizacional está presente em toda a empresa, desde a elaboração do projeto da empresa até a finalização da venda do produto, passando por todo ciclo econômico-financeiro.

Os primeiros estudos apresentados por Cyert e March (1963), Bourgeois (1981) e Sharfman et al. (1988) servem como plataforma teórica para as demais pesquisas, mas os autores seguintes não convergem ao estabelecer um modelo de mensuração e operacionalização da folga organizacional nas organizações. Além disso, no decorrer dos anos, os pesquisadores do tema vêm agregando outras definições às já existentes sobre folga organizacional, o que comprova a forma complexa com que folga organizacional se apresenta na literatura e nas organizações.

Considerando-se os antecedentes de folga organizacional preconizados por Sharfman et al. (1988) e utilizados no estudo de Sender (2004), observou-se nos três níveis de análise dos antecedentes de folga organizacional - indústria, organização e grupos de interesse - que os artigos se distribuiram de forma quase igual, sendo 13 nas duas primeiras categorias e 12 artigos na última. De modo geral, nas pesquisas evidenciadas, observa-se que, em sua maioria, se classificam quanto à inovação, tecnologia e desempenho. Nota-se também que a problemática evidenciada nessas pesquisas está em torno do avanço tecnológico e modernização dos processos de atividades, o que culmina na chamada Era digital.

A classificação quanto aos grupos de interesse é vista como elemento central nos estudos, pois representa a autonomia de decisão da empresa. No entanto, a sua operacionalização é contraditória, pois mensuração de poder de decisão é uma forma intangível de dado e, por conseguinte, de aferição. Na verdade, podem-se mensurar os resultados do poder de decisão, mas não se consegue ter controle sobre o tipo de folga organizacional que esse poder de decisão pode ocasionar em uma organização.

Por último, em relação às disciplinas das ciências sociais aplicadas que abordam o tema folga organizacional, observa-se predominância na área da administração (inovação, tecnologia e desempenho). Na área contábil, foi identificada uma pesquisa de Indjejikian e Matejka (2006), que mediram a influência da folga organizacional entre os controllers das unidades de negócios nas empresas descentralizadas e a forma como os sistemas de gestão contábil afetam a folga organizacional. Essa pesquisa mostra uma das identificações de folga organizacional dentro das organizações, o que alerta que a contabilidade não pode ignorar os tipos de folga organizacional que podem ser gerenciados em uma organização.

Recomenda-se, para futuros estudos, a análise da abordagem de pesquisas sobre folga organizacional realizadas no Brasil e sua publicação em periódicos e eventos científicos nacionais. Também se recomenda investigar sobre modelos de mensuração das folgas organizacionais nessas pesquisas para operacionalizar a medição do tamanho da folga em diferentes aspectos do ambiente organizacional. 


\section{REFERÊNCIAS BIBLIOGRÁFICAS}

ANTLE, Rick; EPPEN, Gary D. Capital rationing and organizational slack in capital budgeting. Management Science, v. 31, n. 2, p. 163-174. February, 1985.

ANTLE, Rick; FELLINGHAM, John. Resource rationing and organizational slack in a two-period model. Journal of Accounting Research, v. 28, n. 1, p. 01-24, 1990.

BANSAL, Pratima. From issues to actions: the importance of individual concerns and organizational values in responding to natural environmental issues. Organization Science, v. 14, n. 05, p. 510-527, 2003.

BATEMAN, Thomas S; ZEITHAML, Carl P. The psychological context of strategic decisions: a model and convergent experimental findings. Strategic Management Journal, v. 10, p. 59-74, 1989.

BOURGEOIS III, L. J. On the measurement of organizational slack. Academy of Management Review, v. 6, n. 1, p. 29-39, 1981.

BOWEN, Frances E. Organizational slack and corporate greening: broadening the debate. British Journal of Management, v. 13, p. 305-316, 2002.

BROMILEY, Philip. Testing a causal model of corporate risk taking and performance. Academy of Management Journal, v. 34, n. 01, p. 37-59, 1991.

CHATTOPADHYAY, Prithviraj; GLICK, William H; HUBER, George P. Organizational actions in response to threats and opportunities. Academy of Management Journal, v. 44, n. 05, p. 937-955, 2001.

CHEN, Wei-Ru; MILLER, Kent D. Situational and institutional determinants of firms' R\&D search intensity. Strategic Management Journal, v. 28, p. 369-381, 2007.

CHENG, Joseph L. C; KESNER, Idalene F. Organizational slack and responseto environmental shifts: the impact of resource allocation patterns. Journal of Management, v. 23, n. 01, p. 1-18, 1997.

CHILD, J. Organizational structure, environment, and performance: the role of strategic choice. Sociology, v. 6, n. 1, p. 2-22, 1972.
COEHN, M. D; MARCH, J. G; OLSEN, J. P. A garbage can model of organizational choise. Administrative Science Quarterly, v. 17, n. 1, p. 1-25, 1972.

CYERT, R. M; MARCH, J. G. A behavioral theory of the firm. Englewood Cliffs. N.J.: Prentice-Hall, 1963.

DAMANPOUR, Fariborz. The adoption of technological, administrative and ancillary innovations: impact of organizational factors. Journal of Management, v. 13, n. 4. p. 675-688, 1987.

. Organizational innovation: a meta-analysis of effects of determinants and moderators. Academy of Management Journal, v. 34, n. 3, p. 555-590, 1991.

DANNEELS, Erwin. Organizational antecedents of second-order competences. Strategic Management Journal, n. 29, p. 519-543, 2008.

DAVIS, Gerald F; STOUT, Suzanne K. Organization theory of market for corporate control: A dynamic Analysis of the characteristics of large takeover targets1980-1990. Administrative Science Quaterly, n. 37, p. 605-633, 1992.

DEMBLA, Pamila; PALVIA, Prashant; BROOKS, Lloyd. Organizational adoption of web-enabled services for information dissemination. Journal of Information Science and Technology, p. 24-49, 2007.

DIMMICK, D. E; MURRAY, V. V. Correlates of substantive policy decisions in organizations: the case of human resource management. Academy of Management Journal, v. 21, n. 4, p. 611-623, 1978.

DUIZENDSTRAAL, Anton; NENTJES, Andries. Organizational slack in subsidized nonprofit institutions. Public Choice, n. 81, p. 297-321, 1994.

GARY, Michael Shayne. Implementation strategy and performance outcomes in related diversification. Strategic Management Journal, n. 26, p. 643-664, 2005.

GEIGER, Scott W; CASHEN, Luke H. A multidimensional examination of slack and its impact on innovation. Journal of Managerial Issues, v. 14, n. 01, p. $68-84,2002$. 
GEORGE, Gerard. Slack resources and the performance of privately held firms. Academy of Management Journal, v. 48, n. 4, p. 661-676, 2005.

GEPPERT, Mike. Paths of managerial learning in the East German context. Organization Studies, p. 249268, 1996.

GREVE, Henrich R. A behavioral theory of R\&D expenditures and innovations: evidence from shipbuilding. Academy of management Journal, $v$. 46, n. 06, p. 685-702, 2003.

HAMBRICK, Donald C; D'AVENI, Richard A. Large corporate failuries as downward spiral. Administrative Science Quaterly, n. 33, p. 1-23, 1988.

HAVEMAN, Heather A. Organizational size and change: diversification in the savings and loan industry after deregulation. Administrative Science Quarterly, v. 38, p. 20-50, Mar. 1993.

HEROLD, David M; JAYARAMAN, Narayanan; NARAYANASWAMY, C. R. What is the relationship between organizational slack and innovation? Journal of Managerial Issues, v. 18, n. 3, p. 372-392, 2006.

INDJEJIKIAN, Raffi J.; MATEJKA, Michal. Organizational slack in decentralized firms: the role of business unit controllers. The Accounting Review, v. 81, n. 4, p. 849-872, 2006.

IYER, Dinesh N; MILLER, Kent D. Performance feedback, slack, and the timing of acquisitions. Academy of Management Journal, v. 51, n. 04, p. 808-822, 2008.

LATHAM, Scott F; BRAUN, Michael R. The performance implications of financial slack during economic recession and recovery: observations from the software industry (2001-2003). Journal of management Issues, v. 20, n. 01, p. 30-50, 2008.

LEE, Ruby P.; GREWAL, Rajdeep. Strategic responses to new technologies and their impact on firm performance. Journal of Marketing, v. 68, p. 157171, Out. 2004.

LITSCHERT, Robert J.; BONHAM, T. W. A conceptual model of strategy formation. Academy of Management Review, p. 211-219, Apr. 1978.
LOVE, E. Geoffrey; NOHRIA, Nitin. Reducing slack: the performance consequences of downsizing by large industrial firms 1977-93. Strategic Management Journal, v. 26, p. 1087-1108, 2005.

$M A R C H$, J. G. Ambiguity and the engineering of choice. International Studies of Management and Organizations, v. 9, p. 9-39, 1979.

MARCH, J. G; OLSEN, J. P. Ambiguity and choise in organizations. Bergen, Norway: Universitetsforlaget, 1976.

MARINO, Kenneth E.; LANGE, David R. Measuring organizational slack: a note on the convergence and divergence of alternative operational definitions. Journal of Management, v. 9, n. 01, p. 81-92, 1983.

MILLER, Kent D; LEIBLEIN, Michael J. Corporate riskreturn relations: returns variability versus downside risk. Academy of Management Journal, v. 39, n. 01, p. 91-122, 1996.

MISHINA, Yuri; POLLOCK, Timothy G; PORAC, Joseph F. Are more resources always better for growth? Resources stickiness in market and product expansion. Strategic Management Journal, v. 26, p. 1179-1197, 2004.

MOSES, O. Douglas. Organizational slack and risktaking behavior: tests of product pricing strategy. Journal of Organizational Change Management, v. 5, n. 3, p. 38-54, 1992.

NOHRIA, Nitin; GULATI, Ranjay. Is slack good or bad for innovation? Academy of Management Journal, v. 39, n. 5, p. 1245-1264, 1996.

PINSONNEAULT, Alain; KRAEMER, Kenneth L. Exploring the roleof information technology in organizational downsizing: A tale of two American cities. Organization Science, v. 13, n. 02, p. 191208, 2002.

POYNTER, T. A.; WHITE, R. E. The strategies of foreign subsidiaries: responses to organizational slack. International Studies of Management and Organizations, v. 14, n. 04, p. 91-106, 1985.

PRIETULA, Michael J; WATSON, Harry S. Extending the Cyert-March duopoly model: organizational and economics insight. Organization Science, v. 11, n. 5, p. 565-585, 2000. 
RICHTNÉR, Anders; AHLSTRÖM, Pär. Influences on organisational slack in new product development projects. International Journal of Innovation Management, v. 10, n. 4, p. 375-406, 2006.

SENDER, Gisela. O papel da folga organizacional nas empresas: um estudo em bancos brasileiros. 2004. 226f. Dissertação (Mestrado em Administração)-Instituto de Pós-Graduação em AdministraçãoUniversidade Federal do Rio de Janeiro, Rio de Janeiro, 2004.

SHARFMAN, Mark P. et al. Antecedents of organizational slack. Academy of Management Review, v. 13, n. 04, p. 601-614, 1988.

SINGH, Jitendra V. Performance, slack and, risk taking in organizational decision making. Academy of Management Journal, v. 29, n. 03, p. 562-585, 1986.

TAN, Justin; PENG, Mike W. Organizational slack and firm performance during economic transitions: two studies from an emerging economy. Strategic Management Journal, n. 24, p. 1249-1263, 2003.

THOMPSON, J. D. Organization in action. New York: McGraw-Hill, 1967.
THOMSON, Neil; MILLAR, Carla C.J.M. The role of slack in transforming organizations: a comparative analysis of east german and Slovenian companies. Int. Studies of Mgt. e Org., v. 31, n. 02, p. 65-83, 2001.

VOSS, Glenn B; SIRDESHMUKH, Deepak; VOSS, Zannie Giraud. The effects of slack resources and environmental threat on product exploration and exploitation. Academy of Management Review, v. 51, n. 01, p. 147-164, 2008.

WALLY, Stefan; FONG, Cher-Min. Effects of firm performance, organizational slack, and debt on entry timing: a study of ten emerging product markets in USA. Industry and innovation, v. 07, n. 02, p. 169183, 2000.

YOUNG, Michael N. The impact of capital markets on compensation incentives, organizational slack, and firm innovation. Academy of Management proceending's, 1999.

ZAJAC, Edward J; GOLDEN, Brian R; SHORTELL, Stephen M. New organizational forms for enhancing innovation: The case of internal corporate joint ventures. Management Science, v. 37, n. 02, p. 170-184, Feb.1991. 